Letter to Editor:

\title{
New Evolutionary Gamification in Patient's Education
}

\author{
Banafsheh Ghorbani $^{1}$ (D), Fatemeh Bahramnezhad ${ }^{1 *}$ (i)
}

1. Department of Critical Care Nursing, School of Nursing and Midwifery, Tehran University of Medical Sciences, Tehran, Iran.

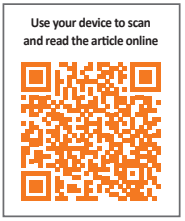

ditation Ghorbani, B. \& Bahramnezhad, F., 2018. New Evolutionary Gamification in Patient's Education. Journal of Client-Centered Nursing Care, 4(3), pp. 173-174. https://doi.org/10.32598/jccnc.4.3.173

https://doi.org/10.32598/jccnc.4.3.173

Patient's education as the core of nursing care is one of the essential rights of the patients, too. Nurses should apply effective and applicable methods to teach their patients properly. The role of healthcare team, especially nurses, is very important in adopting suitable educational methods and consequently patients' adherence to their treatment regimens. The World Health Organization (WHO) has frequently pointed out that appropriate patient's education during discharge helps them adhere to their treatment regimens and this in turn leads to the shorter hospitalization, lower mortality rate, and consequently better health economics (Maningat, Gordon \& Breslow 2013).

Regarding the importance of patient's education, North American Nursing Diagnosis Association (NANDA) and Nursing Intervention Classification (NIC) have seriously highlighted the risk of ineffective patients' treatment regimens due to unawareness or incorrect awareness as a nursing diagnosis (Butcher et al. 2018; Gordon 2014). According to previous studies, patient's education is insufficient, and effective educational methods should be employed for people at different age groups and with different literacy levels to improve their understanding about disease conditions and treatment processes (Chi \& Demiris 2015).

In the meantime, some authorities believe that with the development of science and technology, the importance of direct educational methods such as lectures, face to face education, group discussions, and teach-back methods is declining and indirect methods such as video games, web-based education, and so on are new opportunities that should be explored.

Accordingly, people are becoming more interested in using these indirect methods because of their advantages such as wide access, interesting presentation, and using them at any time or place. In recent years, an indirect educational method known as Gamification (GF) has been introduced (Sardi, Idri \& Fernández-Alemán 2017). This approach was proposed by Detereding et al. (2011). In particular, GF refers to the components that are used in games and implemented in designing applied relationships, so that electronic transactions become quick and enjoyable.

This method provides interaction, reward, and motivation to encourage change in behavior, increase motivation to learn new skills, or increase participation through playing. Indeed, in this educational approach, game and mechanical components are designed for certain purposes such as education and not for playing. Besides their benefits for the patients, they improve interdisciplinary interactions among experts (AlMarshedi, Wills \& Ranchhod 2015). This kind of game is not limited to a certain age group and all people can benefit it.

* Corresponding Author:

Fatemeh Bahramnezhad, PhD.

Address: Department of Critical Care Nursing, School of Nursing and Midwifery, Tehran University of Medical Sciences, Tehran, Iran Tel: +98 (913) 3974856

E-mail: bahramnezhad@sina.tums.ac.ir 
The use of game components in different contexts increases people's motivation, interaction, and pleasure. Moreover, the sense of success and passing a level of game are encouraging. Moreover, this approach increases social interactions, promotes problem-solving ability, and gains support from people around. Despite vast use of this education method, GF is still a concept and there is no agreement on its accurate definition. Through different studies, GF has been used for teaching patients with different diseases and problems like heart failure, myocardial infarction, rheumatoid arthritis, diabetes, breast cancer, smoking, blood pressure control, and Alzheimer with gaining positive results (Sardi, Idri \& Fernández-Alemán 2017; Krasulak 2016). The use of this method has now been increased in developed countries. This method introduced by Anna Sort, a Spanish nursing expert.

In patient's education context, development and implementation of GF can be an effective step in education process (Kapp 2012; Huang \& Soman 2013; Fleming et al. 2017). Patients by having this application in their smart phones have full time access to their required educations and a combination of game components and scientific educations can provide better and enjoyable learning experience with quicker feedback and easier remembrance of the content (Johnson et al. 2016; McKeown et al. 2016).

With the development of technology, everyone has now access to social networks, and by using this new education method, interdisciplinary interactions increase. Thanks to new communication devices like smart phones, this method can be used to make the education more attractive and motivating for the learners.

\section{References}

AlMarshedi, A., Wills, G. B. \& Ranchhod, A., 2015. The wheel of sukr: A framework for gamifying diabetes self-management in Saudi Arabia. Procedia Computer Science, 63, pp. 475-80. [DOI:10.1016/j.procs.2015.08.370]

Butcher, H. K., et al., 2018. Nursing Interventions Classification (NIC)-E-Book. Amsterdam: Elsevier Health Sciences.

Chi, N. C. \& Demiris, G., 2015. A systematic review of TeleHealth tools and interventions to support family caregivers. Journal of Telemedicine and Telecare, 21(1), pp. 37-44. [DOI:10.1177/1357633X14562734] [PMID] [PMCID]

Deterding, S., et al., 2011. From game design elements to gamefulness: Defining Gamification. Paper presentrd at the $15^{\text {th }}$ International
Academic MindTrek Conference: Envisioning Future Media Environments, Tampere, Finland, 28-30 September 2011.

Fleming, T. M., et al., 2017. Serious games and Gamification for mental health: Current status and promising directions. Frontiers in Psychiatry, 7, p. 215. [DOI:10.3389/fpsyt.2016.00215]

Gordon, M., 2014. Manual of nursing diagnosis. Burlington, Massachusetts: Jones \& Bartlett Publishers. [PMCID]

Huang, W. H. Y. \& Soman, D., 2013. Gamification of education-research report series: Behavioural economics in action. Toronto, Canada: Rotman School of Management, University of Toronto.

Johnson, D., et al., 2016. Gamification for health and wellbeing: A systematic review of the literature. Internet Interventions, 6 , pp. 89-106. [DOI:10.1016/j.invent.2016.10.002]

Kapp, K. M., 2012. The Gamification of learning and instruction: game-based methods and strategies for training and education. Hoboken, New Jersey: John Wiley \& Sons.

Krasulak, M., 2016. Use of Gamification in the process of selection of candidates for the position in the opinion of young adults in Poland. Jagiellonian Journal of Management, 1(3), pp. 203-15.

Maningat, P., Gordon, B. R. \& Breslow, J. L., 2013. How do we improve patient compliance and adherence to long-term statin therapy. Current Atherosclerosis Reports, 15(1), pp. 291. [DOI:10.1007/s11883-012-0291-7]

McKeown, S., et al., 2016. Gamification as a strategy to engage and motivate clinicians to improve care. Healthcare Management Forum, 29(2), pp. 67-73. [DOI:10.1177/0840470415626528]

Sardi, L., Idri, A. \& Fernández-Alemán, J. L., 2017. A systematic review of Gamification in e-Health. Journal of Biomedical Informatics, 71, pp. 31-48. [DOI:10.1016/j.jbi.2017.05.011] 